\title{
A Systemic Functional Study of the English Nominal Group as Interpersonal and Textual Grammatical Metaphor
}

\author{
Manliang $\mathrm{Li}^{1}$ \\ ${ }^{1}$ School of Foreign Languages, Inner Mongolia University, Hohhot, China \\ Correspondence: Manliang Li, School of Foreign Languages, Inner Mongolia University, Hohhot 010021, Inner \\ Mongolia Autonomous Region, China. Tel: 86-0471-499-6235. E-mail: limanliang95@sina.com.cn
}

\author{
Received: November 11, 2014 Accepted: December 30, 2014 Online Published: February 25, 2015 \\ doi:10.5539/ells.v5n1p47 \\ URL: http://dx.doi.org/10.5539/ells.v5n1p47
}

\begin{abstract}
The English nominal group is a significant grammatical unit in English, and its internal structure is very complex. Grammatical metaphor is one of the key concepts in systemic functional linguistics and the study of grammatical metaphor can be conducted from the experiential, the interpersonal and the textual perspectives. The literature to date shows that grammatical metaphor is a crucial property in English and it is mostly studied in relation to the English clauses. Grammatical metaphor in relation to the English nominal group can also be explored from the three perspectives. This paper aims to discuss how grammatical metaphor is related to the English nominal group from the interpersonal and the textual perspectives. The data used in this paper are all obtained from literature of English grammar by observation. Meanwhile, this research adopts a qualitative, descriptive and explanatory method, and analyses the English nominal group as interpersonal and textual grammatical metaphor on the basis of the metafunctions in systemic functional linguistics. The findings show that interpersonal and textual grammatical metaphor is also a property of the English nominal group.
\end{abstract}

Keywords: the English nominal group, interpersonal and textual grammatical metaphor, systemic functional linguistics

\section{Introduction}

This paper aims to explore how interpersonal and textual grammatical metaphor is related to the English nominal group. Like metafunctions, grammatical metaphor is also a significant element of systemic functional linguistics (SFL hereafter). Li (2014) has discussed the English nominal group as experiential grammatical metaphor. Likewise, the English nominal group as grammatical metaphor can also be discussed from the interpersonal and textual perspectives. This study will do a tentative filling of this blank. Consequently, this paper will investigate the English nominal group as grammatical metaphor from the interpersonal and the textual perspectives.

At the beginning, we shall have a brief introduction to the data to be used in this research, and the methodology to be adopted in this paper. This is followed by a literature review in which the basic concepts of grammatical metaphor in SFL in general, and the interpersonal grammatical metaphor and the textual grammatical metaphor in particular will be presented. From there, the analysis progresses to the core section of this paper, findings and discussion, which is the exploration of the English nominal group as interpersonal and textual grammatical metaphor. The last section is the concluding remarks, which summarizes the findings of the whole paper as well as the implications and suggestions for the future research relevant to this research.

\section{Data and Methodology}

Data play a significant role in conducting scientific studies. As Widdowson (2000, pp. 72-75) argues, there are broadly three sources to obtain the data of linguistics: by introspection, by elicitation, and by observation. By introspection, researchers appeal their "own intuitive competence as the data source" (ibid., p. 72). This tradition has long been in operation, and thus the researcher can invent examples as the data of investigation in linguistic studies. The second way of getting data is by elicitation, which means the researcher draws on the intuitions of the other members of the community to find out "whether a particular combination of linguistic element is grammatically possible in their language, or what would be an appropriate expression given a particular context" (ibid., p. 73). The data obtained by introspection and elicitation are the data of competence or the abstract knowledge of a language. Data of performance or the actual language behaviour can be collected by observation, 
which refers to "the idea that behaviour, e.g., language use, can be observed naturalistically" (Huang \& Ghadessy, 2008 , p. 18). To examine the actual use of a particular linguistic item in existing corpora is a typical way of getting data by observation.

Bloor and Bloor (2001, p. 4) point out that "an important feature of Halliday's approach to linguistic study is its insistence on studying actual instances of language that have been used (or are being used) by speakers or writers". Butler (1985, p. 15) states that the SFL approach is corpus-based, and it "object[s] to the practice of using self-created examples as evidence" (Yang, 2003, p. 7). The Chomskyan approach focuses "too much on theory at the expense of describing real language in use" (Fawcett, 2008, p. 9). These statements imply that the SFL approach collects data mainly by observation. However, Fawcett (2006, p. 258) points out that "we should not be afraid to create new examples - i.e., 'invented examples' - by thinking systemically — and then testing them in thought experiments and by checking them in large corpora". In this sense, examples obtained by introspection are not contradicted to the actual behavior by observation because introspection is based on thinking systematically and the invented examples can be tested in corpora. The data used in the present research are collected mainly by observation. Most examples are taken from the literature on English grammar or linguistics. Meanwhile, only a very few examples are obtained by introspection.

Our research method adopted in this research is qualitative, descriptive and explanatory. We explore certain constructions on the premise that similar constructions can be depicted in an identical way. The basic purpose animating our research is to determine how meaning is realized through varieties of options or forms. Thus, our study not only describes the English nominal group as interpersonal and textual grammatical metaphor but also explains why the functional analysis is as it is.

\section{Literature Review}

\subsection{Basic Concepts of Grammatical Metaphor in SFL}

\subsubsection{Metaphor as a Figure of Speech}

First, we shall look at the term metaphor as a kind of figure of speech together with simile, metonymy or synecdoche. According to Richards, Platt and Platt (2000, p. 174), figure of speech refers to "a word or phrase which is used for special effect, and which does not have its usual or literal meaning". Baldick (1990, p. 83) also holds that a figure of speech is "an expression that departs from the accepted literal sense or from the normal order of words, or in which an emphasis is produced by patterns of sound". These two definitions nearly share the same sense that figure of speech is concerned with how a certain expression is used, literally or metaphorically, and that we ought not to understand an expression through looking at its literal sense.

It is not adventurous to say that simile and metaphor are the two types that are most frequently used. Both of them concerns the comparison of two entities or concepts, one of which is the source domain and the other of which is the target domain $(\mathrm{Hu}, 2011, \mathrm{p} .135)$. The two concepts share some similarities. The difference between simile and metaphor lies in the occurrence of the simile marker, like and as. Baldick (1990, p. 134) points out that metaphor is the most important and widespread figure of speech and it refers to "one thing, idea, or action is referred to by a word or expression normally denoting another thing, idea ,or action, so as to suggest some common quality shared by the two". For example, the sentence $O$ my love is like a red, red rose (Burns, 1961, p. 126) contains the use of simile because of the use of the simile marker like. But when we say my love is a red, red rose, we use a metaphor, in which my love is the target domain and a red, red rose is the source domain.

\subsubsection{Grammatical Metaphor in SFL}

The concept of grammatical metaphor in SFL has connections with and distinctions from metaphor as a kind of figure of speech. Besides, Halliday (2000) regards synecdoche and metonymy as a subtype of metaphor since all the three concern the non-literal use of certain words. They are similar to the lexical metaphor in SFL. Hu (2000, p. 33) points out that grammatical metaphor is an intrinsic property of language and grammatical metaphor may exist in human language as long as men survive. Halliday (2000) observes that metaphor in SFL is actually lexicogrammatical metaphor rather than simply lexical metaphor. Simply speaking, lexical metaphor examines what meanings a certain form has. Namely, a form may have different meanings, metaphorical or literal. On the other hand, however, grammatical metaphor explores how the same meaning is realized by different forms, either congruent form/wording or metaphorical form/wording. As a matter of fact, the relationship between language form and meaning is not always straightforward. Fawcett $(2000$, p. 197) argues that "it is not the case that a syntactic unit always corresponds in a one-to-one manner to the event or object, to which it refers, i.e., to its equivalent conceptual representation in the belief system". Congruently, a clause realizes an event and a nominal group realizes an object. When a nominal group is used to refer to an event or happening rather than an 
object, grammatical metaphor finds it place. The new term congruent can be simply defined as "closer to the state of affairs in the external world" (Thompson, 2008, p. 222), while metaphorical form is "the expression of a meaning through a lexico-grammatical form that originally evolved to express a different kind of meaning" (ibid., p. 223). In other words, metaphor is either "variation in the use of words" (Halliday, 2000, p. 341) or "variation in the expression of meanings" (ibid.). This demonstrates the distinction between lexical metaphor and grammatical metaphor. For more information about the concept of grammatical metaphor, see Halliday (1985, 2000), Halliday and Matthiessen $(2004,2008)$, and Thompson $(2000,2008)$.

Halliday (2000) analyzes two main types of grammatical metaphor with regard to the English clause, the ideational metaphor and the interpersonal metaphor. Martin (2004) and Thompson $(2000,2008)$ argue the existence of the textual metaphor as a major property of the English clause. As was stated earlier, we have analyzed the English nominal group as experiential grammatical metaphor, and the following section will only discuss the interpersonal and textual grammatical metaphor.

\subsection{Metafunctional Grammatical Metaphor}

People use language to do different things. In other words, language has different functions, which are termed as metafunctions in SFL. Consequently, grammatical metaphor is connected with the three metafunctions and can be subdivided into the experiential, the interpersonal, and the textual metaphors. Halliday (2000) discusses two types of metafunctional grammatical metaphor, the ideational and the interpersonal metaphor, the former including the Transitivity metaphor and the latter including the Mood and Modality metaphor. Thompson (2000, 2008) and Martin (2004) prove the existence of the textual grammatical metaphor as a significant property of the English clause. This section will briefly look at these three types of metaphors with examples.

\subsubsection{Interpersonal Grammatical Metaphor}

In the aspect of the interpersonal metafunction, Mood and Modality are the two core concepts, and similarly the interpersonal metaphor mainly falls upon the metaphor of Modality and the metaphor of Mood. Halliday (2000, pp. 354-367) provides detailed discussion on these two concepts, and we shall review these two kinds of interpersonal metaphors in a very simple and brief way.

Usually, Modality is realized by modal verbs in English, but more often than not it can also be realized by other classes of units such as the adverbial group and the clauses at the lexicogrammatical level. Grammatical metaphor is a matter of degree and it lies in "the intermediate ground between positive and negative polarity" (Halliday, 2000, p. 356). Example 1 below is to explain the concept in this sense.

\section{Example 1:}

(1a) Probably he is right. (congruent)

(1b) I think he is right. (metaphorical) (cited in Huang, 2000, p. 35)

In (1a), Modality is realized by the adverbial group probably indicating the probability. Superficially, the example in (1b) is a hypotactic clause complex consisting of the dominant projecting clause $I$ think and the dependent projected clause he is right. When looked into further, the dominant projecting clause does not express the propositional meaning but functions as the Modality. In terms of the function in the structure, it has the same function as probably does in (1a), and the propositional meaning is realized by the projected dependent clause. In other words, the Modality of probability is not realized by the modal expression like probably in the congruent form, but by the projecting clause. Comparatively speaking, the item probably is closer to the state of affairs of the external world than I think in expressing the Modality.

The Mood metaphor is closely related to the expression of the speech function, namely, giving or demanding information or goods and/or service by statement, question, offer and command. Congruently, a question is supposed to demand information, a statement to give information, an offer to give goods and/or service, and a command to demand goods and/or service. At the lexicogrammatical level, they are respectively realized by the interrogative clause, the indicative clause, and the imperative clause. The Mood metaphor finds its place if the interrogative clause is employed to express a command or if the indicative clause is used to express a question. We shall use the following examples to illustrate this concept, and for the sake of convenience, we number it as Example (2) here.

Example 2:

(2a) Open the door, please. (Congruent)

(2b) Will you open the door? (Metaphorical) 
(2c) Do you mind opening the door? (Metaphorical)

(2d) Could you help me by opening the door? (Metaphorical)

(2e) Would you like to open the door? (Metaphorical) (cited in Huang, 2002)

These five clauses all express the identical propositional meaning, open the door, which is to demand service. Example (2a) is an imperative clause and it is considered as the congruent form. The other four clauses express the similar meaning of a command but they are all interrogative clauses, which are congruently to seek information or goods and/or service. Consequently, they are all the metaphor of Mood in contrast to the imperative one as the congruent wording.

This section so far has provided a very simple and general overview of the interpersonal metaphor by Modality and Mood. In fact, the actual situation is more complicated than what are concerned here, and for more details see Halliday (2000), Halliday and Matthiessen (2004, 2008), and Hu et al. (2005).

\subsubsection{Textual Grammatical Metaphor}

In SFL, we have the textual metafunction together with the ideational metafunction and the interpersonal metafunction. However, Halliday $(1985,2000)$ does not mention the textual metaphor, and thus the textual metaphor becomes a controversial concept. Martin (2004) and Thompson $(2000,2008)$ include it as a type of metafunctional grammatical metaphor and argue that it has the identical position to the other two types. On the other hand, however, although Halliday (2000) does not include it as a type of metaphor in his framework, he does not say the textual metaphor does not exist. We shall use the following examples to explain this concept, and we number it as Example (3).

Example 3:

(3a) We walk the ring with our dogs. Afterwards, we just wait.

(3b) We walk the ring with our dogs and then we just wait.

(3c) After we walk the ring with our dogs we just wait.

(3d) Subsequent to walking in the ring with our dogs we just wait.

(cited in Martin, 2004, p. 168)

It is obvious that the four clauses differ from each other as the result of the application of different textual devices rather than of the transference of Process, Modality or Mood, as is the case of the other two types of metafunctional metaphors dealt with in the above sections. Among the four options, (3a) consists of two clauses connected by the cohesive conjunction afterwards. From (3b) to (3d), each is a clause complex composed of two clauses containing two Processes respectively realized by the verbal group walk and wait. By delicacy, (3b) is a paratactic clause complex in which the two clauses are connected by the paratactic conjunction and; (3c) is a hypotactic clause complex, and the dependent clause is introduced by the hypotactic conjunction after; (3d) is also a hypotactic clause complex, but its dependent clause is a non-finite one and it is introduced by the hypotactic expression subsequent to.

In practice, it is hard to identify which is congruent and which is metaphorical, but we do find that the distinction of these four options lies in the use of the different textual devices, or more accurately the different kinds of conjunctions. The degree of congruence and metaphor of them can be explained as follows. If one is a beginner of English language, one may choose to use two simple clauses for it is hard for a beginner to combine two clauses into one following certain grammatical rules. Then, the paratactic structure is more complex than the two independent clauses, but simpler than the hypotactic construction. Likewise, the non-finite hypotactic structure is even more complex than the finite one. In other words, these four options reflect the degree of complexity in terms of the clause structure in expressing the identical meaning. Example (3a) is the easiest one and (3d) is the most difficult one, and in our terms (3a) is the most congruent one and (3d) is the most metaphorical one. The easiest one is closer to the state of the external world, and thus it is more congruent than the complex ones in expressing the same propositional meaning. For more details on textual metaphor, see Martin (2004).

To sum up, this section so far has introduced the concept of the grammatical metaphor in SFL from three perspectives. First, we discussed the distinction between the lexical metaphor and the grammatical metaphor, and then we went on with the congruent wording and the metaphorical wording as well as the relationship between them. Next, we moved on to the central part of this section dealing with the metafunctional metaphor, which is the core theoretical basis for the subsequent discussion with regard to the English nominal group as grammatical metaphor. The three types of metafunctional metaphor, the experiential, the interpersonal and the textual, are 
examined with examples. Although these concepts are directly associated with the English clauses, they provide basic framework to analyze other classes of units. In other words, these basic principles can be applied to the analysis of the English nominal group as grammatical metaphor, which will be conducted in the sections below.

\section{Findings and Discussion}

\subsection{The English Nominal Group as Interpersonal Grammatical Metaphor}

Halliday (2000) does not offer the interpersonal analysis of the English nominal group, but he points out the distinction between the Experiential Epithet and the Interpersonal Epithet. This suggests that the elements of the nominal group have many options in expressing the identical meaning. The term identical here is a concept of relativity because any choice may mean differently. Generally speaking, the grammatical metaphor is connected with the English nominal group in two perspectives, the nominal group as the grammatical metaphor and the nominal group elements as the grammatical metaphor. In other words, the English nominal group as metaphorical form is contrasted to other grammatical forms, such as clauses, the verbal group or the adjectival group. Our discussion on the experiential grammatical metaphor basically concentrated on the nominal group as a whole as the grammatical metaphor. Meanwhile, the elements of the nominal group can also construe the grammatical metaphor in various ways. The interpersonal metaphor of the English nominal group is mainly concerned with the elements within the nominal group.

The sense of congruence and metaphor is actually a matter of degree, which is demonstrated in Table 1 below.

Table 1. Congruent and metaphorical expressions as a matter of degree

\begin{tabular}{|c|c|c|}
\hline a crippled child & a disabled child & a child who cannot use his arms and legs properly \\
\hline
\end{tabular}

This table above gave three ways of describing a child with specific property. We can look at the relationship between the two nominal groups, a crippled child and a disabled child, when they both depict a child who cannot use his arms and legs properly. We get a figure (Figure 1). Evidently, this figure does not show how the certain word is used, but how the same meaning is realized differently.

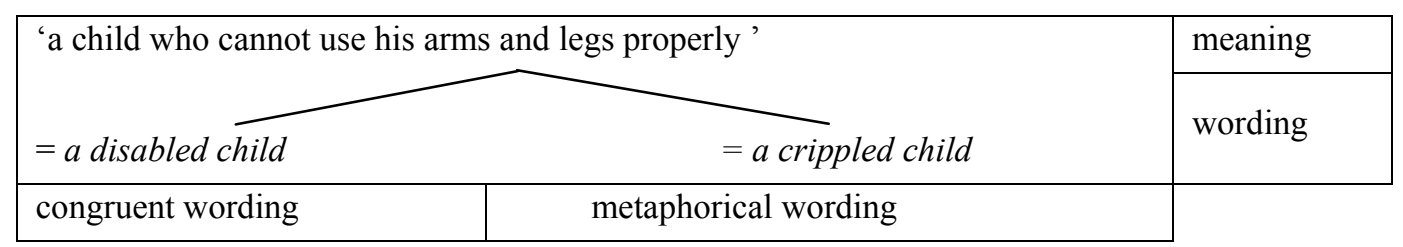

Figure 1. Congruent and metaphorical wordings of the same meaning

Usually, the nominal group a disabled child is treated as a kind of euphemism in terms of the figure of speech, and it is actually the usual expression of the state of the child who has difficulty in using his or her arms or legs properly and thus it is the congruent wording. On the contrary, a crippled child has derogatory color, and thus it is the metaphorical wording. The distinction between the two nominal groups is concerned with the different forms expressing the nearly identical meaning, and in this sense the different expressions might have the degree of grammatical metaphor. The child's mother, for instance, would consider the nominal group a child who cannot use his arms and legs properly is the most congruent wording and a crippled child the most metaphorical wording.

On balance, when one uses a nominal group in communication, written or spoken, to depict a Thing, one would consciously or unconsciously choose the most appropriate wording in order to maintain or establish harmonious interpersonal relationship. The most appropriate wording is used compared with other similar wordings. These different wordings must concern one's personal affection, and the different wordings thus bear the sense of the interpersonal grammatical metaphor. At the lexicogrammatical level, one is supposed to choose the appropriate wording to every element in the nominal group. The particular Epithet to be used reflects the Modality in one way or another. 


\subsection{The English Nominal Group as Textual Grammatical Metaphor}

Halliday (2000), as well as other systemic functional linguists, does not provide as equal analysis to the English nominal group from the textual metafunctional perspective as from the experiential perspective. $\mathrm{Li}$ and $\mathrm{Du}(2012)$ conducted an exploratory analysis of the textual structure of the English nominal group with of-phrase as the Qualifier. The exploration indicates that the Head and the Premodifier of the nominal group play the role of the Theme and Given Information and the Qualifier of the nominal group plays the role of the Rheme and the New Information when the preposition of functions as a Minor Process. The analysis may suggest that the internal structure of the English nominal group can be examined from the textual perspective.

In Section 3.2 above, we looked at the textual grammatical metaphor in the English clause and clause complex, and saw that the congruent wording and the metaphorical wording are achieved by the textual devices, such as independent clauses, a paratactic clause complex, a hypotactic clause complex consisting of two finite clauses and a hypotactic clause complex made up of a finite clause and a non-finite clause. In the similar sense, the Qualifier of the English nominal group can be realized by various forms, and these different realizations might be viewed from the perspective of grammatical metaphor. When the same meaning is realized in different forms, these different forms must have the degree of being more congruent or more metaphorical. The following examples are the different wordings expressing nearly the same propositional meaning.

Example 4:

(4a) the students outside the classroom

(4b) the students who were standing outside the classroom

(4c) the student standing outside the classroom

(4d) as many students as could be gathered outside the classroom (cited in Zhang, 1995, p. 636)

These four instances express the same meaning, the students stand outside the classroom. According to our analysis above, the clause the students stand outside the classroom would be the congruent form, and the nominal group forms would be the metaphorical forms. However, here we discuss the degree of congruence among the four nominal group options. The first three options are distinguished from one another by the different Qualifiers, an adverbial group in (4a), a finite relative clause in (4b), and a non-finite clause in (4c). The adverbial group outside the classroom functions as the Adjunct in the rank-shifted clause in (4b) and (4c), and it is not the immediate element of the nominal group. Similar to the example (3), (4a) is the most congruent form and (4d) is the most metaphorical form. As to (4d), the structure is more complicated in that the Premodifier as many has close connection with not only the Head but also the Qualifier of the nominal group. The Qualifier of the nominal group is realized by a finite clause with the adverbial group as the Adjunct. Comparatively, (4d) is even more metaphorical than the other three forms. As the distinction of these four options is due to the different grammatical or textual devices, it is appropriate to regard the grammatical metaphor alike as the textual grammatical metaphor.

The textual grammatical metaphor with regard to the English nominal group must have many other situations, and the subsequent part of this section will discuss another frequent case. Halliday (1994/2000, p. 188) observes that nearly all the Qualifiers are rank-shifted. However, there are still other possibilities in which the rank-shifted Qualifiers are converted into Premodifiers based on certain rules. In the following part, we shall give three types of nominal groups.

\section{Type 1:}

(1) a moderate-sized building $=$ a building of moderate size

(2) a good-mannered man $=$ a man of good manners

(3) apple seeds $=$ the seeds of an apple

(4) a radio program $=$ a program on the radio (cited in Zhang, 1995, p.p. 636-637)

\section{Type 2:}

(1) a twelve-year-old boy = a boy of twelve / a boy who is twelve years old

(2) the far-and-wide discussed new product

(3) his never-too-old-to-learn spirit

(4) six do-nothing months

(5) a do-it-yourself tool 
(6) a never to be forgotten day

(7) a dearly paid for mistake

(8) those well nourished and well brought up children

(9) the many times repeated warning = the warning which has been reported many times (cited in Zhang, 1995, pp. 636-637)

\section{Type 3:}

(1) She has asked I don't know how many people to the party. [I don't know how many people she has asked to the party.] (cited in Quirk et al., 1985, p. 1322)

(2) today's meet the people (if they can find you) tour (cited in Quirk et al., 1985, p. 1337)

(3) His other comments ignore ... the obvious fallacies inherent in the 'But the poem (play, novel) was meant to be tedious/pretentious/pointless' line of critical argument. (cited in Quirk et al., 1985, p. 1337)

The items good-mannered and apple seeds in Type 1 are sometimes regarded as compound words, which Richards, Platt and Platt (2000, p. 89) define as "a combination of two or more words which functions as a single word". The structure of compound words is beyond the scope of investigation in the framework of SFL. However, the Premodifiers of the nominal group in Type 2 cannot be simply treated as compound words. Rather, their structures have more characteristics of a nominal group than of a compound noun. Moreover, in Type 3, it is the clause that functions as the Premodifier of the nominal group, and apparently the clauses of this kind cannot be considered as compound words. Thus, we do not treat the examples here as compound words but as nominal groups. When it comes to the structure of the nominal group, the items preceding the Head have the property of rank-shift.

In fact, it is not our main aim to discuss whether these Premodifiers are called compound words or not. What we are concerned about is the fact that whatever they are called they function as the Premodifier of the nominal group. There must be some distinctions between the nominal group when they function as the Premodifier and the nominal group when they serve as the Qualifier. The distinction of this kind reveals the principle that the meaning is expressed in different wordings, which bear the degree of congruence or the degree of metaphor.

The usual state would be the rank-shifted units, especially the clause, as the Qualifier of the nominal group. In this sense, the clause as the Qualifier would be the congruent wording, and the clause as the Premodifier would be a kind of grammatical metaphor. The clause or clause-like expression as the Premodifier has "a flavor of originality, convention-flouting, and provisional or nonce awkwardness" (Quirk et al., 1985, p. 1336), and it seems a rarely occurring phenomenon compared with the clause as the Qualifier. However, the significance of a language phenomenon cannot be decided by its frequency of occurrence. On the contrary, any language phenomenon is significant, because it is not supposed to be ignored as long as it is used. Meanwhile, the literature to date suggests that SFL attaches little significance to this phenomenon in the nominal group.

We shall take one nominal group from each type above to see how grammatical metaphor finds its place in these expressions. The Head or the Thing of the two nominal groups apple seeds and the seeds of an apple falls on the item seeds, and the distinction between them is that the Classifier apple in the first nominal group is the Complement of the prepositional phrase functioning as the Qualifier in the second nominal group. It is hard to distinguish which wording is more congruent and which one is more metaphorical. When it comes to another nominal group, the far-and-wide discussed new product, the congruent form would be the new product discussed far and wide.

When the clause is functioning as the Modifier, the property of being metaphorical is more evident. If we take the first example in Type 3 for an example, we note that the two different wordings denote the identical meaning: I don't know the number of people she has asked to the party. The analysis of this kind is shown in Table 2 that follows.

In the first wording, the clause functions as the Modifier to the headword people, but in the second wording the clause, I don't know, is the dominant clause and the expression how many serves as the Modifier to the Head people. The clause, she has asked, is the dominant clause in the first wording but the Qualifier of the nominal group in the second one. As to the prepositional phrase to the party, it is associated in both cases with the Predicator asked, and functions as the Complement of the clause. The only difference is that it is embedded in the dominant clause in the first case but in the relative clause in the second. 
Table 2. Analysis of the nominal group with the clause as the Premodifier

\begin{tabular}{lllll}
\hline She & has asked & I don't know how many & people & to the party. \\
\hline \multirow{2}{*}{ Subject } & Finite Predicator & Premodifier & Head & Complement \\
\cline { 3 - 5 } & don't know & Complement & & \\
\hline & & how many & people & She has asked to the party. \\
\hline \multirow{2}{*}{ Subject } & Finite Predicator & Premodifier & Head & Postmodifier / Qualifier \\
\cline { 3 - 5 } & & Complement & & \\
\end{tabular}

If we look at the transference between the two different wordings demonstrated in the above examples by attaching importance to whether the items functions as the Qualifier or the Modifier of the nominal group, the grammatical metaphor in this sense belongs to the experiential category, which will not be discussed here. Rather, we shall discuss the grammatical metaphor of this kind from the textual perspective.

Textual meaning "tends to be realized by the order in which things occur" (Halliday, 2000, p. 190) and "the unmarked focus information in a nominal group is on the word that comes last, not the word that functions as Thing" (ibid., p. 191). In Table 3 below, we use the similar approach to analyze the textual structure of the nominal groups we are dealing with in this section, and we renumber them as Pair 1, Pair 2 and Pair 3.

Table 3. Analysis of the textual structure of the nominal group

\begin{tabular}{lll}
\hline Given Information & New Information \\
\hline \multirow{2}{*}{ Pair 1} & $\begin{array}{l}\text { apple } \\
\text { seeds }\end{array}$ & $\begin{array}{l}\text { seeds } \\
\text { of an apple }\end{array}$ \\
\hline \multirow{2}{*}{ Pair 2} & $\begin{array}{l}\text { the far-and-wide discussed new } \\
\text { the new product }\end{array}$ & $\begin{array}{l}\text { product } \\
\text { discussed far and wide }\end{array}$ \\
\hline \multirow{2}{*}{ Pair 3} & $\begin{array}{l}\text { Idon't know how many } \\
\text { how many people }\end{array}$ & $\begin{array}{l}\text { people } \\
\text { she has asked to the party }\end{array}$ \\
\hline
\end{tabular}

Some of the nominal groups, such as apple seeds, in the above examples do not have a Qualifier, which means it is unnecessary or hard to identify the thematic structure of the group. In this section, we only discuss the information structure of the nominal group in the above table. The distribution of Given Information and New Information of each pair of the nominal group is different. The New Information is either realized by the Head of the nominal group, seeds, product and people, or by the Qualifier of the nominal group, of an apple, discussed far and wide and she has asked to the party.

On the other hand, based on Halliday's arguments on information focus, which is on the last word of the nominal group (2000, p. 191), we can at least say that the information focus of the two wordings in each pair is different. Thus, if we consider the transference of them is a kind of grammatical metaphor, it is the textual grammatical metaphor. It might be appropriate to regard the second wording in each pair as the congruent wording and the first wording as the metaphorical, for rank-shifted units as the Qualifier is closer to the usual state of the English nominal group structure.

To sum up, the English nominal group as the grammatical metaphor can be investigated from the textual perspective. The analysis can be done in many aspects, and this section only discusses two cases, one of which is to observe the nominal group expressing the same meaning with various types of Qualifier and the other of which is to examine the focus of information of the nominal group when the rank-shifted Qualifier is converted into the Premodifier. In both cases, the nominal group implies the degree of being more congruent or more metaphorical as a result of the elements that differ in one way or another. With the similar approach, the textual metaphor of the English nominal group can be explored in many other ways.

\section{Summary and Conclusion}

This paper investigated the connection between the grammatical metaphor and the English nominal group from the interpersonal and the textual perspectives with regard to the interpersonal and textual metafunctions in SFL, the interpersonal grammatical metaphor and the textual grammatical metaphor. The beginning section was concerned with the connection as well as the distinction between several pairs of closely related concepts: metaphor as a type of figure of speech and grammatical metaphor in SFL, the lexical metaphor and the grammatical metaphor, and the congruent wording and the metaphorical wording. In what follows, we gave a brief overview of the basic concepts of the two types of metafunctional grammatical metaphors in SFL. These 
principles are mainly oriented at the English clause, but we then conducted an exploratory analysis of the English nominal group as grammatical metaphor from the two perspectives.

The conclusions can be summarized as follows: (1) When there are various options to realize the same propositional meaning, grammatical metaphor finds its place, and this is true to the English nominal group. Besides, the English nominal group as grammatical metaphor can be explored in the interpersonal and the textual perspectives. (2) As a result of the option of different Modifiers, especially Epithet, and Qualifiers of the English nominal group, the interpersonal grammatical metaphor is found in the English nominal group. As long as one uses appropriate nominal groups in particular context to express one's ideas in order to establish and maintain harmonious interpersonal relationship in communication, one may use the interpersonal grammatical metaphor. (3) The English nominal group has various types of Qualifiers, and consequently different forms of Qualifier may make the nominal group have the sense of grammatical metaphor. Besides, when the rank-shifted Qualifier is converted into the Premodifier, changes occur to the focus of information of the whole nominal group accordingly. The grammatical metaphor of these two types is closely associated with the textual devices, and therefore it is better categorized as the textual grammatical metaphor. (4) In view of the tremendous complexity of the English nominal group in terms of its internal structure and its syntactic functions, the present paper has only dealt with a very small part of its connection with grammatical metaphor. In other words, the English nominal group as grammatical metaphor can be explored from other perspectives.

\section{Acknowledgments}

This research is financially supported by the national project: A Contrastive Study of the English and Chinese Nominal Groups: A Systemic Functional Approach. First and foremost, I would like to express my sincere gratitude to my MA and PhD supervisor, Professor Huang Guowen at Sun Yat-sen University, to whom this research owes much. I am also grateful to Professor Robin Fawcett at Cardiff University for his constructive suggestions.

\section{References}

Baldick, C. (1990). The Concise Oxford Dictionary of Literary Terms. Oxford: Oxford University Press.

Bloor, T., \& Bloor M. (2001). The Functional Analysis of English: A Hallidayan Approach. Beijing: Foreign Language Teaching and Research Press.

Burns, R. (1961). O my love is like a red, red rose. In O. Williams (Ed.), The Golden Treasury of the Best Songs and Lyrical Poems. New York: The New American Library of World Literature, Inc.

Butler, C. S. (1985). Systemic Linguistics: Theory and Applications. London: Batsford.

Fawcett, R. P. (2000). A Theory of Syntax for Systemic Functional Linguistics. Amsterdam: Benjamins. http://dx.doi.org/10.1075/cilt.206

Fawcett, R. P. (2006). Establishing the Grammar of "Typicity" in English: An Exercise in Scientific Inquiry. In G. W. Huang, C. G. Chang \& F. Dai (Eds.), Functional Linguistics as Appliable Linguistics (pp. 159-262). Guangzhou: Sun Yat-sen University Press.

Fawcett, R. P. (2008). Invitation to Systemic Functional Linguistics through the Cardiff Grammar: An extension and simplification of Halliday's Systemic Functional Grammar (3rd ed.). London: Equinox.

Halliday, M. A. K. (1985). An Introduction to Functional Grammar (1st ed.). London: Arnold.

Halliday, M. A. K. (2000). An Introduction to Functional Grammar (2nd ed.). Beijing: Foreign Language Teaching and Research Press.

Halliday, M. A. K., \& Matthiessen, C. M. I. M. (2004). An Introduction to Functional Grammar (3rd ed.). London: Arnold.

Halliday, M. A. K., \& Matthiessen C. M. I. M. (2008). Construing Experience through Meaning: A Language-based Approach to Cognition. Beijing: World Publishing Corporation.

Hu, Z. L. (2000). The Role of Process and Nominalization in Grammatical Metaphor. In G. W. Huang \& Z. Y. Wang (Eds.), Discourse and Language Functions. Beijing: Foreign Language Teaching and Research Press, 26-33.

Hu, Z. L. (Ed.). (2011). Linguistics: A Course Book (4th ed.). Beijing: Peking University Press.

Hu, Z. L., Zhu, Y. S., Zhang, D. L., \& Li, Z. Z. (2005). Xitong Gongneng Yuyanxue Gailun ("A Survey of Systemic-Functional Linguistics"). Beijing: Peking University Press. 
Huang, G. W. (2000). Cleft Sentences as Grammatical Metaphors. In G. W. Huang \& Z. Y. Wang (Eds.), Discourse and Language Functions (pp. 34-41). Beijing: Foreign Language Teaching and Research Press.

Huang, G. W. (2002). Gongneng Yupian Fenxi Mianmian Guan (“Aspects of Functional Discourse Analysis”). Guowai Waiyu Jiaoxue ("Foreign Language Teaching Abroad"), (4), 25-32.

Huang, G. W., \& Ghadessy, M. (2008). How to Write a Dissertation in English. Beijing: Higher Education Press.

Li, M. L. (2014). A Systemic Functional Study of the English Nominal Group as Grammatical Metaphor. International Journal of Business and Social Science, 5, 63-71.

Li, M. L., \& Du, H. Y. (2012). A Systemic Functional Analysis of the English Nominal Group with the Prepositional Phrase as the Qualifier. Journal of University of Science and Technology Beijing (Social Sciences Edition), (2), 25-30.

Martin, J. R. (2004). English Text: System and Structure. Beijing: Peking University Press.

Quirk, R., Greenbaum, S., Leech, G., \& Svartvik J. (1985). A Comprehensive Grammar of the English Language. London: Longman.

Richards, J. C., Platt J., \& Platt, H. (2000). Longman Dictionary of Language Teaching and Applied Linguistics. Beijing: Foreign Language Teaching and Research Press.

Thompson, G. (2000). Introducing Functional Grammar (1st ed.). Beijing: Foreign Language Teaching and Research Press.

Thompson, G. (2008). Introducing Functional Grammar (2nd ed.). Beijing: Foreign Language Teaching and Research Press.

Widdowson, H. G. (2000). Linguistics. Shanghai: Shanghai Foreign Language Education Press.

Yang, B. J. (2003). A Study of Non-finite Clauses in English: A Systemic Functional Approach. Beijing: Foreign Language Teaching and Research Press.

Zhang, Z. B. (1995). Xinbian Yingyu Yufa Jiaocheng ("A New English Grammar Course Book”). Shanghai: Shanghai Foreign Language Education Press.

\section{Copyrights}

Copyright for this article is retained by the author(s), with first publication rights granted to the journal.

This is an open-access article distributed under the terms and conditions of the Creative Commons Attribution license (http://creativecommons.org/licenses/by/3.0/). 